\title{
Unit per Microliter
}

National Cancer Institute

\section{Source}

National Cancer Institute. Unit per Microliter. NCI Thesaurus. Code C67468.

An arbitrary unit of substance concentration equal to the concentration at which one microliter of mixture contains one unit of a substance. 